\title{
Evolution of the AMCP Format for Formulary Submissions
}

\author{
John B. Watkins, PharmD, MPH, BCPS; Sean D. Sullivan, BScPharm, PhD; \\ Elizabeth Sampsel, PharmD, MBA, BCPS; D. S. "Pete" Fullerton, PhD; \\ Jennifer S. Graff, PharmD; Richard N. Fry, RPh; Jeff Lee, PharmD, FCCP. \\ Iris M. Tam, PharmD, FAMCP; and Steven G. Avey, MS, RPh, FAMCP
}

A MCP's Format for Formulary Submissions is a groundbreaking document describing the evidence required by health care decision makers to support formulary and coverage policy decisions, thus, shaping the dialogue between pharmaceutical and medical device manufacturers and payer pharmacists and physicians and improving their evaluations. Since its adoption by AMCP in October 2000, the AMCP Format has been through 4 major and several minor revisions, maintaining the original vision to create a platform for efficient exchange of scientific information about a pharmaceutical product. Within this framework, manufacturers can share comprehensive clinical and pharmacoeconomic information (including off-label data) with health care decision makers upon their unsolicited request. From its inception, the authors of the AMCP Format have believed that an open dialogue would benefit patients by helping payers and providers make more thorough assessments of emerging products and improve availability of high value treatments to patients that need them

\section{Conceptual Origins of the Format}

Evidence for new drugs is much more available now than in the 1990s, when Professor David Eddy, who directed the Center for Health Policy at Duke University, and others became dissatisfied with traditional methods of clinical decision making. ${ }^{1}$ Eddy discussed the application of epidemiologic methods to patient-level decisions in a JAMA series, "Clinical decision making," from 1990 to $1996,{ }^{2,3}$ followed by the long-running series "Users' Guides to the Medical Literature" by Oxman et al. (1993). ${ }^{4}$ Forward-thinking managed care pharmacists and academics began incorporating principles of evidence-based medicine in formulary development and clinical practice guidelines. Among these innovators was Jim Carlson at Seattle-based Group Health Cooperative of Puget Sound. ${ }^{5}$

As evidence-based medicine gained traction, health policymakers became concerned about information asymmetry between pharmaceutical manufacturers and decision makers in payer and provider organizations. It was difficult or impossible for payers to obtain detailed clinical trial reports and outcomes

J Manag Care Spec Pharm. 2020;26(6):696-700

Copyright $\odot 2020$, Academy of Managed Care Pharmacy. All rights reserved. assessments until well after approval by the U.S. Food and Drug Administration (FDA). Evidence accessible to payers was often limited to manufacturers' product information marketing materials and Pink Sheet summary reports of FDA advisory committee meetings. Without complete high-quality evidence, thorough evaluation by payers was limited.

In 1992, Congress asked the Office of Technology Assessment (OTA) — an office of the U.S. Congress from 1972 to 1995 that provided Congress with objective analysis of complex scientific and technical issues - to evaluate health technologies, including "literature syntheses, outcomes research, cost-effectiveness analysis, practice guidelines development" and other areas. The 1994 OTA report called for evaluating new as well as existing technologies, focusing on patient outcomes rather than intermediate endpoints and making evidence available to decision makers. ${ }^{6}$ Subsequently, Neumann et al. (1996) noted that manufacturers were beginning to use pharmacoeconomic data in promotions. ${ }^{7}$ Kessler et al. (1994) described "Therapeutic Class Wars-Promotion in a Competitive Marketplace." ${ }^{8}$ Publication of the first edition of the textbook Cost Effectiveness in Health and Medicine in 1996 added to the interest in economic evaluation of drugs. ${ }^{9}$ The FDA generally did not evaluate peer-reviewed cost-effectiveness literature, even though the industry "had a history of performing pharmacoeconomic studies without scrutiny of their validity."

Professor Sean Sullivan at the University of Washington (UW) School of Pharmacy invited Paul Langley from Latrobe University to visit the UW in 1994 to discuss the novel 1991 Australian guidelines for informing drug coverage by the Pharmaceutical Benefits Advisory Committee (PBAC), which incorporated cost-effectiveness analysis. ${ }^{10}$ The result was Langley and Sullivan's 1996 seminal article outlining a framework for developing evidence submission guidelines for decision makers in the United States. ${ }^{11}$ The challenge was to apply these principles in our complex multipayer and provider environment. In 1994, Regence BlueShield, a large regional health plan in Seattle, whose independent Pharmacy and Therapeutics (P\&T) Committee was chaired by Sullivan, created guidelines for review of new and existing drugs, incorporating the framework of Langley and Sullivan. 


\section{The Regence Guidelines Project}

Implementing the first Regence guidelines, pharmacy staff found that adequate evidence was not available in a timely fashion. Unpublished studies and information on unapproved indications were difficult to obtain, and humanistic and economic data were not routinely provided by industry. Time required for pharmacists to assemble and synthesize the information was excessive. ${ }^{12}$ To address these needs, a more practical guidance document was developed by Sullivan and UW postdoctoral fellows Dell Mather and Darren Augenstein, based on approaches being developed in Australia, England, and Canada. This document was approved by Regence in June 1997 and implemented in a 2-year pilot program, the results of which were published in $1999 .{ }^{12}$ Regence asked manufacturers to supply their evidence in a comprehensive product dossier "addressing the clinical outcomes and economic consequences of using a proposed product." The dossier contained several sections later included in the AMCP Format: disease description, product description, anticipated place in therapy, clinical studies, economic evaluations, and a disease-based economic model. The success of this pilot project paved the way for development of the AMCP Format.

\section{The AMCP Format Is Launched}

Meanwhile, AMCP leadership became interested in the use of dossiers to help payers obtain the necessary information to provide cost-effective quality health care through a publicly accountable process that reduces variation in formulary decisions. ${ }^{13}$ They challenged payers to assess outcomes of care, quality, cost-effectiveness, and overall value. Langley was asked to provide input because of his association with the PBAC in Australia. Subsequent discussions with Sullivan and the Regence team led to the AMCP Format Version 1.0, released in October 2000. ${ }^{14}$ The Format Executive Committee, a multistakeholder group representing payers, manufacturers, consultants, and academic experts, was appointed to advise AMCP regarding the ongoing maintenance of the Format, with Sullivan as its first chair. The Format Executive Committee has since authored 3 subsequent major versions and several minor revisions that were approved by the Board of Directors. These revisions are summarized in Table 1.

Seeing the potential of this approach, Premera Blue Cross, also in Seattle, incorporated the AMCP Format into its formulary process in May 2001. This provided a solid platform for Premera's biotechnology management initiative in $2005^{14}$ and for the Value-Based Formulary in 2010. ${ }^{15,16}$ Version 4.0 of the AMCP Format addressed new trends including biosimilars, comparative effectiveness research, companion diagnostics and devices. For guidance on modeling economic outcomes, it made reference to ISPOR's best practice guidance for costeffectiveness and budget impact models. ${ }^{17-21}$ The most recent version, Version 4.1, provides guidance for the communication of information about unapproved products and indications in the form of pre-approval dossiers in response to the 21st Century Cures Act and the FDA Final Guidance on industry communications with payers. ${ }^{22-24}$

\section{Stakeholder Training}

In 2001-2002, members of the Format Executive Committee began laying the groundwork for its dissemination Presentations were conducted for the FDA, the National Committee for Quality Assurance, the Centers for Medicare \& Medicaid Services, and pharmaceutical manufacturers. The Foundation for Managed Care Pharmacy (FMCP) contracted with UW faculty to provide 2-day training sessions in Vancouver, San Diego, Orlando, Dallas, Chicago, and Boston. Attendees learned how to use the AMCP Format and how to critically evaluate and apply clinical and pharmacoeconomic information from dossiers to formulary decisions through lectures and practical exercises in a structured but open environment that addressed the practical issues that formulary reviewers face. By 2002, FMCP reported that nearly 20 managed care organizations, 35 hospitals, and several Medicaid programs had adopted the AMCP Format.

AMCP received considerable feedback after these public sessions. In general, manufacturers felt that the AMCP Format provided an opportunity to convey the value of a product, including more latitude for economic analyses and evidence; however, they expressed concerns about payer reviewers proficiency, impact on payer relationships, confidentiality of submissions, and the AMCP Format's unsolicited request. They worried that sensitive proprietary information submitted in a dossier (models and unpublished studies) could become publicly available to competitors and might alarm regulatory authorities. ${ }^{25}$ Payers were concerned about staff resources and expertise to properly evaluate dossier contents. The Format Executive Committee worked diligently to address these concerns in subsequent revisions.

Clearly, more training was needed. FMCP offered 1-day training programs at spring and fall AMCP conferences from October 2002 to October 2005, with emphasis on understanding and using economic information and a live exercise evaluating a cost-effectiveness model. A recorded version of this course was produced in 2005. In 2006, the basic course was replaced by more advanced training at AMCP meetings through 2012. AMCP estimates that more than 1,100 individuals were trained in over 55 programs, including manufacturer training and shorter sessions at other professional and trade association meetings. Symposia for industry professionals were offered at the 2005 and 2006 AMCP Annual Meetings. Webinars and sessions at AMCP Nexus meetings have been used to educate stakeholders about the more recent revisions. Several program faculty have been involved, and corporate sponsors have supported these programs over time. Sponsors were never involved in determining program content. 


\section{TABLE 1 Evolution of the AMCP Format over the Past 20 Years with Key Features of Each Version}

\begin{tabular}{|c|c|c|}
\hline Version and Date & Committee Chair & Significant New Features and Emphasis \\
\hline $\begin{array}{l}1.0 \\
\text { October } 2000\end{array}$ & Sean Sullivan & $\begin{array}{l}\text { - Formalized and standardized information requirements } \\
\text { - Covered basic concepts, structure, and unsolicited request process } \\
\text { - Provided generic template for MCOs, adaptable to individual plan needs } \\
\text { - Stated core requirements for formulary submissions by pharmaceutical manufacturers: } \\
\text { o Disease description } \\
\text { o Product description } \\
\text { o Supporting clinical evidence } \\
\text { o Economic evaluations } \\
\text { o Disease-based economic model } \\
\text { - Focused formulary decisions on health plan-wide impact } \\
\text { - Was neither static nor overly prescriptive }\end{array}$ \\
\hline $\begin{array}{l}2.0 \\
\text { October } 2002\end{array}$ & Sean Sullivan & $\begin{array}{l}\text { - Clarified issues addressed in version } 1 \\
\text { - Provided guidance on adoption } \\
\text { - Described process for dossier submission to a payer } \\
\text { - Addressed stakeholder comments received since publication of version } 1\end{array}$ \\
\hline $\begin{array}{l}2.1 \\
\text { June } 2005\end{array}$ & Sean Sullivan & $\begin{array}{l}\text { - Addressed confidentiality of manufacturer proprietary information in dossiers } \\
\text { - Emphasized trust and open dialogue } \\
\text { - Set forth presentation requirements for cost-effectiveness and budget impact models }\end{array}$ \\
\hline $\begin{array}{l}.0 \\
\text { January } 2010\end{array}$ & Sean Sullivan & $\begin{array}{l}\text { - Stated unsolicited request guidelines } \\
\text { - Addressed process for requests to update existing dossiers } \\
\text { - Included executive summary to communicate clinical and economic product value } \\
\text { - Added section for other supporting evidence } \\
\text { - Provided section for place in therapy } \\
\text { - Addressed evidence for pharmacogenomics tests and drugs } \\
\text { - Expanded and clarified economic value and modeling report section } \\
\text { - Clarified modeling expectations }\end{array}$ \\
\hline $\begin{array}{l}3.1 \\
\text { December } 2012\end{array}$ & Pete Penna & $\begin{array}{l}\text { - Discussed use of comparative effectiveness research in dossiers } \\
\text { - Added evidence requirements for specialty pharmaceuticals } \\
\text { - Added evidence requirements for companion diagnostics }\end{array}$ \\
\hline $\begin{array}{l}4.0 \\
\text { April } 2016\end{array}$ & Jeff Lee & $\begin{array}{l}\text { - Encouraged rigorous, relevant, ongoing scientific dialogue with manufacturers } \\
\text { - Included considerations of the evolving environment, including biosimilars, medical devices, comparative } \\
\text { effectiveness research, and companion diagnostic tests } \\
\text { - Provided logistical guidance on developing and updating dossiers } \\
\text { - Added guidance for providing evidence before FDA approval } \\
\text { - Referenced CER Collaborative tools codeveloped by AMCP, ISPOR, and the National Pharmaceutical Council } \\
\text { that help payers evaluate real world evidence, and provide continuing education }{ }^{34-38}\end{array}$ \\
\hline $\begin{array}{l}4.1 \\
\text { January } 2020\end{array}$ & Iris Tam & $\begin{array}{l}\text { - Encouraged bidirectional communication between manufacturers and decision makers } \\
\text { - Addressed and incorporated preapproval information exchange (PIE) } \\
\text { - Provided new dossier format and guidance for Unapproved Product dossiers } \\
\text { - Provided new dossier format and guidance for Unapproved Use dossiers (unapproved use of approved products } \\
\text { for which FDA approval is sought) }\end{array}$ \\
\hline
\end{tabular}

AMCP = Academy of Managed Care Phamacy; $C E R=$ comparative effectiveness research; FDA=U.S. Food and Drug Administration; ISPOR=International Society for Pharmacoeconomics and Outcomes Society; $\mathrm{MCO}=$ managed care organization.

While managed care organizations requested dossiers, most reported using only the clinical evidence and disease background sections, not the economic models. Researchers questioned the relationship between dossier submission and formulary acceptance, ${ }^{26-30}$ and a study assessing the quality of dossier economic models found mixed results. ${ }^{31}$ Some researchers had misunderstood the dossier's goal of facilitating accurate product assessment through presentation of both positive and negative features thus preventing formulary placement of a low-value product.

\section{Electronic Dossier Delivery}

When the AMCP Format began, most dossiers were submitted as printed binders. In 2007, AMCP and Dymaxium, developer of FormularyDecisions, began discussing a web-based eDossier platform that would meet regulatory standards. Dymaxium's Bridget Olson and Allen Lising developed a successful prototype, proactively engaging the FDA to address regulatory concerns. ${ }^{32}$ This was presented at the 2009 AMCP Annual Meeting. Discussions with early decision-maker influencers helped FormularyDecisions meet reviewers' challenges with 
large volumes of information. In March 2010, AMCP and Dymaxium launched a pilot eDossier platform with over 200 decision makers. In 2012, use of the eDossier platform was included in the AMCP Foundation P\&T Competition requirements. In 2014, the platform added resources including 150,000 evidence links, health technology assessment insights, reviews by the Institute for Clinical and Economic Review, and other decision-maker tools. ${ }^{33}$ In 2019, FormularyDecisions was acquired by Xcenda.

\section{Future of the AMCP Format}

Over 2 decades, the AMCP Format has adapted to many environmental changes, including the advent of biotechnology and specialty drugs, precision therapies, companion diagnostics, real-world evidence, and patient-centered outcomes. The revision process is designed to adapt to future changes, such as those likely to occur following the disruption of the COVID-19 pandemic. The Format Executive Committee has addressed legal and regulatory concerns, clarifying language to increase stakeholder acceptance. Dossiers made the transition from paper to PDF and then to the internet. Today, the AMCP Format remains best practice guidance for transmission of evidence from manufacturers to health care decision makers. Today's payer pharmacists have little time to meet with manufacturers, but they still need increasingly complex information to conduct comprehensive formulary reviews. In a world that demands efficient communication, the AMCP Format delivers.

\section{Authors}

JOHN B. WATKINS, PharmD, MPH, BCPS, Residency Program Director, Premera Blue Cross, Mountlake Terrace, Washington, and Affiliate Professor of Pharmacy, University of Washington, Seattle. SEAN D. SULLIVAN, BScPharm, PhD, Dean, School of Pharmacy and Professor of Pharmacy, Health Services and Medicine, and D. S. "PETE" FULLERTON, PhD, Affiliate Professor of Pharmacy, University of Washington, Seattle. ELIZABETH SAMPSEL, PharmD, MBA, BCPS, Senior Director, Payer, Provider and Partner Alliances, Xcenda, Palm Harbor, Florida. JENNIFER S. GRAFF, PharmD, Vice President Comparative Effectiveness Research, National Pharmaceutical Council, Washington, DC. RICHARD N. FRY, RPh, Former FMCP Director of Programs, Leland, North Carolina. JEFF LEE, PharmD, FCCP, Associate Dean for Academic Affairs, Lipscomb University College of Pharmacy, Nashville, Tennessee. IRIS M. TAM, PharmD, FAMCP, Senior Director, HEOR, Patient Access \& Value, Coeus Consulting Group, Daly City, California. STEVEN G. AVEY, MS, RPh, FAMCP, Executive Director Emeritus, AMCP Foundation, Alexandria, Virginia.

AUTHOR CORRESPONDENCE: John B. Watkins, PharmD, MPH, BCPS, Residency Program Director, Premera Blue Cross, 7001220 th St., SW, MS432, Mountlake Terrace, WA 98043. Tel.: 425.402.3995; E-mail: formularyguy@hotmail.com.

\section{DISCLOSURES}

No funding was required for this project. The authors are or have been members of the Format Executive Committee.

\section{ACKNOWLEDGMENTS}

The authors thank David Veenstra, Pete Penna, and Dell Mather for reviewing and providing input and Paula Eichenbrenner for sharing many Formatrelated documents from AMCP Foundation records. The authors also thank the various companies that have sponsored Format-related programs and the annual student P\&T competition, through which PharmD students learn to evaluate product dossiers and use the information to write formulary monographs. We are especially grateful to those companies that have volunteered product dossiers for use in the competition.

\section{REFERENCES}

1. Eddy DM, Billings J. The quality of medical evidence: implications for quality of care. Health Aff (Millwood). 1988;7(1):19-32

2. Eddy DM. Clinical decision making: from theory to practice. Anatomy of a decision. JAMA. 1990 19;263(3):441-43.

3. Eddy DM. Clinical decision making: from theory to practice. Benefit language: criteria that will improve quality while reducing costs. JAMA. 1996 28;275(8):650-57.

4. Oxman AD, Sackett DL, Guyatt GH, et al. Users' Guides to the Medical Literature: I. How to Get Started. JAMA. 1993;270(17):2093-95.

5. Carlson JA. Antimicrobial formulary management: meeting the challenge in a health maintenance organization. Pharmacotherapy. 1991;11(1 (Pt 2): 32S-35S.

6. U.S. Congress, Office of Technology Assessment. Identifying Health Technologies that Work: Searching for Evidence. OTA-H-608. Washington, DC: U.S. Government Printing Office; 1994

7. Neumann PJ, Zinner DE, Paltiel AD. The FDA and regulation of costeffectiveness claims. Health Aff (Millwood). 1996;15(3):54-71.

8. Kessler DA, Rose JL, Temple RJ, et al. Therapeutic class wars - drug promotion in a competitive marketplace. N Engl J Med. 1994;331(20);1350-53.

9. Gold MRP, Siegel JE, Russell LB, Weinstein MC. Cost-Effectiveness in Health and Medicine. New York: Oxford University Press; 1996.

10. Henry D. Economic analysis as an aid to subsidisation decisions: the development of Australian guidelines for pharmaceuticals. Pharmacoeconomics. 1992;1(1):54-67.

11. Langley PC, Sullivan SD. Pharmacoeconomic evaluations: guidelines for drug purchasers. Am J Manag Care. 1996;2(6):671-77.

12. Mather DB, Sullivan SD, Augenstein, D, Fullerton DS, Atherly D Incorporating clinical outcomes and economic consequences into drug formulary decisions: a practical approach. Am J Manag Care. 1999;5(3):277-85

13. Fry RN, Avey SG, Sullivan SD. The Academy of Managed Care Pharmacy Format for Formulary Submissions: an evolving standard-a Foundation for Managed Care Pharmacy Task Force report. Value Health. 2003;6(5):505-21.

14. Watkins JB, Choudhury SR, Wong E, Sullivan SD. Managing biotechnology in a network-model health plan: a U.S. private payer perspective. Health Aff (Millwood). 2006;25(5):1347-52

15. Sullivan SD, Yeung K, Vogeler C, et al. Design, implementation, and first-year outcomes of a value-based drug formulary. J Manag Care Spec Pharm. 2015;21(4):269-75. Available at: https://www.jmcp.org/doi/10.18553/ jmcp.2015.21.4.269.

16. Yeung K, Basu A, Hansen RN, et al. Impact of a value-based formulary on medication utilization, health services utilization, and expenditures. Med Care. 2017;55(2):191-98. 
17. Caro JJ, Briggs AH, Siebert U, et al. Modeling good research practices overview: a report of the ISPOR-SMDM Modeling Good Research Practices Task Force-1. Value Health. 2012;15(5):796-803.

18. The AMCP Format for Formulary Submissions: welcome to Version 4.0. J Manag Care Spec Pharm. 2016;22(5):444-46. Available at: https://www. jmcp.org/doi/10.18553/jmcp.2016.16071.

19. Sarnes E, Boswell K. Achieving balance with the AMCP Format for Formulary Submissions, Version 4.0: a dossier producer's perspective. J Manag Care Spec Pharm. 2016;22(5):447. Available at: https://www.jmcp. org/doi/10.18553/jmcp.2016.16095.

20. Pannier A, Dunn JD. AMCP Format for Formulary Submissions, Version 4.0. J Manag Care Spec Pharm. 2016;22(5):448. Available at: https://www. jmcp.org/doi/10.18553/jmcp.2016.16092.

21. Academy of Managed Care Pharmacy. AMCP Format for Formulary Submissions, Version 4.0. April 2016. Available at: http://www.amcp.org/ sites/default/files/2019-03/AMCP-Format-V4.pdf. Accessed May 7, 2020.

22. Academy of Managed Care Pharmacy. AMCP Format for Formulary Submissions, Version 4.1. Available at: https://www.amcp.org/sites/default/ files/2019-12/AMCP_Format\%204.1_1219_final.pdf. Accessed May 7, 2020.

23. Brixner D, Woodward TC, Seifter N, et al. Preapproval information exchange: perspectives of U.S. population health decision makers on preferences for early engagement with investigational therapies. J Manag Care Spec Pharm. 2019;25(2):164-73. Available at: https://www.jmcp.org/doi/10.18553/ jmcp.2019.25.2.164.

24. U.S. Food and Drug Administration. Drug and device manufacturer communications with payors, formulary committees, and similar entities questions and answers: guidance for industry and review staff. June 2018. Available at https://www.fda.gov/downloads/drugs/guidancecomplianceregulatoryinformation/guidances/ucm537347.pdf. Accessed April 23, 2020.

25. Neumann PJ. Foreword to The AMCP Format for Formulary Submissions, Version 2.1. April 2005. Available at https:/www.amcp.org/ sites/default/files/2019-03/Format\%20Version\%202.1\%20April\%202005.pdf. Accessed April 23, 2020.

26. Spooner JJ, Gandhi PK, Connelly SB. AMCP Format dossier requests: manufacturer response and formulary implications for one large health plan. J Manag Care Pharm. 2007;13(1):37-43. Available at: https://www.jmcp.org/ doi/10.18553/jmcp.2007.13.1.37.

27. Lyles A, Watkins JD. Manufacturer response to AMCP Format dossier requests. J Manag Care Pharm. 2007;13(3):290-91. Available at: https://www. jmcp.org/doi/10.18553/jmcp.2007.13.3.290a.
28. Nichol MB, Knight TK, Epstein J, Honda DH, Tretiak R. Opinions regarding the Academy of Managed Care Pharmacy dossier submission guidelines: results of a small survey of managed care organizations and pharmaceutical manufacturers. J Manag Care Pharm. 2007;13(4):360-71. Available at: https://www.jmcp.org/doi/10.18553/jmcp.2007.13.4.360.

29. Asche CV. Opinions regarding the value and use of the AMCP Format still unknown. J Manag Care Pharm. 2007;13(7):609-10. Available at: https:// www.jmcp.org/doi/10.18553/jmcp.2007.13.4.360.

30. Watkins JB, Sullivan SD. The payer's dilemma: recognizing the uncertainty of clinical and economic evidence at product launch. J Manag Care Pharm. 2009;15(2):167-70. Available at: https://www.jmcp.org/doi/10.18553/ jmcp.2009.15.2.167.

31. Colmenero F, Sullivan SD, Palmer JA, et al. Quality of clinical and economic evidence in dossier formulary submissions. Am J Manag Care. 2007;13(7):401-07.

32. Sampsel E, Olson B, Restaino D. Unsolicited requests from companies conducting product evaluation/formulary placement: processes and regulatory/legal considerations for manufacturers. FDLI Update. November/ December 2012, p. 26. Available at: https://www.foxrothschild.com/content/ uploads/2015/05/Update-article-David-Restaino.pdf. Accessed May 7, 2020.

33. Costill D. Connecting payers with the formulary information they need. First Report Managed Care. June 2017. Available at https://www.managedhealthcareconnect.com/taxonomy/term/4656. Accessed May 7, 2020.

34. Berger ML, Martin BC, Husereau D, et al. Questionnaire to assess the relevance and credibility of observational studies to inform health care decision making: An ISPOR-AMCP-NPC Good Practice Task Force report. Value Health. 2014;17(2):143-56.

35. Caro JJ, Eddy DM, Kan H, et al. A modeling study questionnaire to assess study relevance and credibility to inform health care decision making: an ISPOR-AMCP-NPC Good Practice Task Force report. Value Health. 2014;17(2):174-82.

36. Jansen JP, Trikalinos T, Cappelleri JC, et al. Indirect treatment comparison/network meta-analysis study questionnaire to assess relevance and credibility to inform health care decision making: an ISPOR-AMCP-NPC Good Practice Task Force report. Value Health. 2014;17(2):157-73.

37. CER Collaborative. Comparative Effectiveness Research Tool. Available at: https://www.cercollaborative.org/global/default.aspx?RedirectURL=\%2fho me\%2fdefault.aspx. Accessed May 7, 2020.

38. Perfetto EM, Anyanwu C, Pickering MK, et al. Got CER? Educating pharmacists for practice in the future: new tools for new challenges. J Manag Care Spec Pharm. 2016;22(6):609-16. Available at: https://www.jmcp.org/ doi/10.18553/jmcp.2016.22.6.609. 